\title{
Increased Sheep Lung Vascular Permeability Caused by Pseudomonas Bacteremia
}

\author{
Kenneth L. Brigham, William C. Woolverton, Lynn H. Blake, and \\ Norman C. Staub \\ From the Cardiovascular Research Institute and Department of Physiology, \\ University of California, San Francisco, California 94143
}

A B S T R A C T In awake sheep, we compared the responses of lung lymph flow and lymph and plasma protein concentrations to steady state elevations of pulmonary vascular pressures made by inflating a left atrial balloon with those after an intravenous infusion of $10^{5}-10^{10}$ Pseudomonas aeruginosa. Lymph flow increased when pressure was increased, but lymph-plasma protein concentration ratios always fell and lymph protein flow (lymph flow $\times$ lymph protein concentration) increased only slightly. After Pseudomonas, sheep had transient chills, fever, leukopenia, hypoxemia, increased pulmonary artery presssure and lymph flow and decreased left atrial pressure and lymph protein concentration. 3-5 h after Pseudomonas, when vascular pressures and lymph protein concentrations had returned to near base line, lymph flow increased further to 3-10 times base line and remained at a steady level for many hours. During this steady state period, lymph-plasma protein concentration ratios were similar to base line and lymph protein flow was higher than in the increased pressure studies. Two sheep died of pulmonary edema 7 and $9 \mathrm{~h}$ after Pseudomonas, but in 16 studies, five other sheep appeared well during the period of highest lymph flow and all variables returned to base line in 24-72 h. Six serial indicator dilution lung water studies in five sheep changed insignificantly from base line after Pseudomonas. Postmortem lung water was high in the two sheep dead of pulmonary edema and one other, but

A preliminary report of some of the data in this paper has been published (Chest. 65: 51 (Suppl.). 1974).

Dr. Brigham's present address is: Department of Medicine, Vanderbilt University Hospital, Nashville, Tenn.; Dr. Woolverton's present address is: Department of Surgery, Tulane University School of Medicine, New Orleans, La.; and Dr. Blake's present address is: Division of Lung Diseases, National Heart and Lung Institute, Bethesda, Md.

Received for publication 24 January 1974 and in revised form 7 June 1974. six sheep killed 1-6 h after Pseudomonas had normal lung water. Because of the clear difference between the effects of increased pressure and Pseudomonas on lymphplasma protein concentration ratios and lymph protein flow, we conclude that Pseudomonas causes a prolonged increase in lung vessel permeability to protein. Because we saw lung lymph flow as high as 10 times base line without pulmonary edema, we conclude that lung lymphatics are a sensitive high-capacity mechanism for removing excess filtered fluid. An equivalent pore model of sheep lung vessels suggests that the changes we saw after Pseudomonas could result from small changes in the structure of exchanging vessel walls.

\section{INTRODUCTION}

The most frequently recognized cause of acute pulmonary edema is raised pulmonary microvascular pressure due to left heart failure. When pulmonary edema occurs without heart failure, it is ascribed to increased permeability of lung exchanging vessels to plasma protein $(1,2)$. Investigators studying increased permeability lung edema usually have produced fulminant, rapidly progressive edema with toxic chemicals such as alloxan $(3,4)$, EDTA (5), or alphanapthylthiourea (6).

We have found that a slow intravenous infusion of Pseudomonas aeruginosa bacteria into unanesthetized sheep causes a dramatic, prolonged, but reversible increase in pulmonary transvascular fluid and protein flow, out of proportion to changes in vascular pressure. It appears to be an excellent animal model for studying permeability edema. In this paper, we describe our initial experiments and compare the results with the effects of mechanical increases in pulmonary microvascular pressure on lung fluid and protein filtration as reflected in lung lymph. 


\section{METHODS}

We studied nine young female sheep. Over a 2 -wk period we made three thoracotomies ${ }^{1}$ during which we: $(a)$ surgically extirpated abdominal contributions to a large elongated lymph node located in the posterior mediastinum (caudal mediastinal node) by resecting the node below the inferior pulmonary ligaments (7), (b) put catheters for sampling blood and measuring pressures in the left atrium and pulmonary artery, placed a stainless steel clip at the posterior border of the left atrium, put a $16-\mathrm{Fr}$ Foley catheter coated with silicone elastomer (Dow Corning Corp., Midland, Mich.) in the left atrium, and put an inflatable latex cuff (Davol Inc., Providence, R. I.) around the main pulmonary artery, and (c) put a heparin-impregnated silicone elastomer cannula (Dow Corning Corp.) in the main efferent channel from the caudal mediastinal lymph node. We also put catheters in the right atrium and thoracic aorta through the internal jugular vein and carotid artery in the neck. After the animals recovered from surgery, we determined the location of the left atrial clip by fluoroscopy with the sheep standing. We took the 0 reference level for all vascular pressures as $9 \mathrm{~cm}$ below this point, which represents the level of the most dependent part of the lung, as determined by freezing four dead, whole sheep in the prone position, sectioning the thorax on a band saw, and measuring this distance (8).

In all experiments, the sheep stood quietly in a cage with access to food and water. We continuously measured vascular pressures with miniature strain gauges (Micron Instruments, Inc., Los Angeles, Calif.) and an electronic recorder (Honeywell, Inc., Test Instruments Div., Denver, Col.). We calculated pulmonary microvascular pressure $\left(\mathrm{P}_{\mathrm{mv}}\right)^{2}$ from pulmonary arterial $\left(\mathrm{P}_{\mathrm{ps}}\right)$ and left atrial $\left(\mathrm{P}_{1 \mathrm{a}}\right)$ pressures, assuming 0.4 of the resistance downstream to microvessels $\left[\mathrm{P}_{\mathrm{mv}}=\mathrm{P}_{1 \mathrm{a}}+0.4\left(\mathrm{P}_{\mathrm{pa}}-\mathrm{P}_{1 \mathrm{a}}\right)\right]$ (9). We measured lung lymph flow by recording the volume drained into graduated tubes at $15-\mathrm{min}$ intervals. We measured total protein and albumin and globulin concentrations in plasma samples drawn at hourly intervals and in lymph samples pooled at 30 -min intervals. We used the biuret method for measuring total protein (10) and cellulose acetate electrophoresis (Beckman Microzone, Beckman Instruments, Inc., Fullerton, Calif.) for separating the albumin fraction from the remainder of the protein, which was predominantly gamma globulin.

We made peripheral blood white cell and platelet counts using a Coulter counter (model S. Coulter Electronics, Inc., Fine Particle Group, Inc., Hialeah, Fla.) and measured arterial blood $\mathrm{Po}_{2}, \mathrm{PCO}_{2}$, and $\mathrm{pH}$ with a blood gas analyzer (Radiometer, Copenhagen, Denmark). We measured cardiac output and the indicator dilution quantity of water in the lung (idQwl) by injecting a mixture of $\left[{ }^{51} \mathrm{Cr}\right]$ erythrocytes, $\left[{ }^{125} \mathrm{I}\right]$ human serum albumin, and tritiated water into the right atrium and taking samples at 1-s intervals from the aorta. We used both labeled erythrocytes and albumin as intravascular indicators, because in some circumstances in dogs, using albumin alone results in a large underestimate of extravascular lung water (4, 11). We determined ${ }^{51} \mathrm{Cr}$ and ${ }^{125} \mathrm{I}$ radioactivity in the in-

${ }^{1}$ A more detailed description of our surgical techniques will be published separately.

${ }^{2}$ Abbreviations used in this paper: dQ1, dry weight of bloodless lung; idQwl, indicator dilution quantity of water in the lung; L/P, lymph-to-plasma; la, left atrial; $\mathrm{mv}$, microvascular; pa, pulmonary artery. jected solution and in each of the samples in a gamma scintillation spectrometer (model 3002, Packard Instrument Co., Inc., Downers Grove, Ill.), correcting for overlap, and ${ }^{3} \mathrm{H}$ activity in a liquid scintillation counter (model 314EX, Packard Instrument Co.) after ethanol precipitation of the protein. We plotted radioactivity of each indicator relative to the activity of the indicator injected on a $\log$ scale against time after injection on a linear scale, and extrapolated the downslopes for each indicator linearly. We calculated cardiac output as the inverse of the area under the $\left[{ }^{51} \mathrm{Cr}\right]$ red cell curve (12). If areas under the $\left[{ }^{125} \mathrm{I}\right]-$ albumin or tritiated water curves were more than $10 \%$ different from the $\left[{ }^{51} \mathrm{Cr}\right]$ red cell curve, we discarded the study. We calculated mean transit times for each of the indicators by the method of Chinard, Enns, and Nolan (12). To calculate extravascular lung water, we subtracted the mean transit time of a composite of [ $\left.{ }^{125} \mathrm{I}\right]$ albumin and $\left[{ }^{51} \mathrm{Cr}\right]$ red cell mean transit times calculated from the formulas of Goresky, Cronin, and Wangel (11), using hematocrit and whole blood and plasma water content measured gravimetrically in samples taken at the time of each study from the mean transit time of tritiated water, and multiplied this difference by cardiac output and fractional water content of whole blood $(4,11)$.

We made postmortem anatomical and lung fluid analyses as follows. We anesthetized each sheep with pentobarbital, put it supine on a table, inserted a cuffed endotracheal tube and inflated the lungs to $20 \mathrm{~cm} \mathrm{H}_{2} \mathrm{O}$ pressure with air. We opened the chest by a sternum-splitting incision, double cross-clamped a 5-10-g portion of the posterior basilar segment of the lower lobe of one lung, and excised it. It was immediately frozen for histological study by the method of Storey and Staub (13). We then cross-clamped both hila, drew a blood sample from the heart, and removed the lungs. The entire procedure from anesthesia to clamping the hila did not exceed $5 \mathrm{~min}$.

After homogenizing both lungs in a Waring blendor (Waring Products Div., Dynamics Corp. of America, New Hartford, Conn.), we measured the water content of a portion of each homogenate and blood by drying in an $80^{\circ} \mathrm{C}$ oven for $48 \mathrm{~h}$ and measured hemoglobin concentration in blood and the centrifuged supernate of the lung homogenate by the cyanmethemoglobin method (14). Assuming the hemoglobin concentration and water content of blood at death equalled that of residual lung blood, we calculated the amount of lung homogenate water due to residual blood and subtracted this value from total measured homogenate water to get extravascular lung water. Wet weight of bloodless lung is the total wet lung weight minus calculated residual blood, and dry lung weight is wet weight of bloodless lung minus extravascular lung water. We expressed the results as a ratio of extravascular lung water to dry weight of bloodless lung $(\mathrm{Qwl} / \mathrm{dQ} 1)$. These are the same calculations described in detail by Pearce, Yamashita, and Beazell (15).

We compared serial measurements of cardiac output, indicator dilution lung water, peripheral blood white cell and platelet counts, and arterial blood gas tensions and $\mathrm{pH}$ using a paired $t$ test (16). We chose $P<0.05$ as the level of significance.

Experimental protocol. Our protocol required a series of at least three experiments done on different days in each animal: (a) a physiologic test for the presence of systemic lymph, (b) the effect of a steady state increase in pulmonary microvascular pressure, (c) the effect of Pseudomonas aeruginosa infusion. 
TABLE I

Stcady Stale Responses of Lung Lymph Flow and L/P Protein Concentrations to Increased Pulmonary Vascular Pressure and to Pseudomonas Infusion in Seven A wake Sheep

\begin{tabular}{|c|c|c|c|c|c|c|c|c|c|c|}
\hline \multirow[b]{3}{*}{ Sheep no. } & \multirow{3}{*}{$\begin{array}{l}\text { Body } \\
\text { weight }\end{array}$} & \multirow[b]{3}{*}{ Conditions } & \multirow{3}{*}{$\begin{array}{l}\text { Pseudo- } \\
\text { monas } \\
\text { dose }\end{array}$} & \multirow[b]{3}{*}{$\mathrm{P}_{\mathrm{pa}} *$} & \multirow[b]{3}{*}{$\mathrm{P}_{\mathrm{L:}} *$} & \multirow[b]{3}{*}{ Qlym‡ } & \multicolumn{4}{|c|}{ Protein } \\
\hline & & & & & & & \multicolumn{2}{|c|}{ Lymph } & \multicolumn{2}{|c|}{ Plasma } \\
\hline & & & & & & & Alb.\$ & Glob.\$ & Alb. & Glob. \\
\hline & $k g$ & & $\times 10^{8}$ & & & $m l / h$ & & $g / 1$ & & \\
\hline \multirow[t]{3}{*}{ S25-72 } & 32 & base line & & 27 & 13 & 7.4 & 2.66 & 1.56 & 3.04 & 3.31 \\
\hline & & increased $P_{m v} \|$ & & 38 & 25 & 10.8 & 2.25 & 1.13 & 3.12 & 3.54 \\
\hline & & Pseudomonas & 0.025 & 40 & 10 & 52.6 & 2.39 & 1.24 & 2.58 & 2.84 \\
\hline \multirow[t]{3}{*}{ S26-72 } & 44 & base line & & 27 & 11 & 5.8 & 2.51 & 2.62 & 2.64 & 4.06 \\
\hline & & increased $P_{m v}$ & & 50 & 34 & 13.0 & 1.89 & 1.25 & 2.67 & 3.80 \\
\hline & & Pseudomonas & 32 & 35 & 11 & 22.9 & 2.32 & 2.60 & 2.60 & 3.63 \\
\hline \multirow[t]{3}{*}{ S.30-72 } & .38 & base line & & 32 & 16 & 11.6 & 2.48 & 1.82 & 2.87 & 3.36 \\
\hline & & increased $P_{m v}$ & & 43 & 35 & 19.2 & 1.90 & 1.33 & 2.95 & 3.50 \\
\hline & & Pseudomonas & 7.5 & 56 & 9 & 71.4 & 2.05 & 1.42 & 2.66 & 2.90 \\
\hline \multirow[t]{3}{*}{$\mathrm{S} 32-72$} & 34 & base line & & 35 & 12 & 6.1 & 1.99 & 2.82 & 2.21 & 4.54 \\
\hline & & increased $P_{m v}$ & & 50 & 25 & 16.1 & 1.38 & 1.29 & 2.30 & 4.70 \\
\hline & & Pseudomonas & 10 & 57 & 9 & 55.7 & 1.58 & 1.30 & 2.15 & 3.90 \\
\hline \multirow[t]{3}{*}{ S36-72 } & 49 & base line & & 24 & 10 & 10.4 & 2.14 & 2.18 & 2.45 & 4.42 \\
\hline & & increased $P_{m v}$ & & 34 & 23 & 18.2 & 2.09 & 1.90 & 2.59 & 4.67 \\
\hline & & Pseudomonas & 25 & 43 & 6 & 85.3 & 0.72 & 0.92 & 1.76 & 2.84 \\
\hline \multirow[t]{3}{*}{$\mathrm{RS} 2-73$} & 51 & base line & & 31 & 11 & 6.4 & 2.76 & 2.39 & 2.98 & 4.19 \\
\hline & & increased $P_{m v}$ & & 39 & 29 & 12.0 & 2.54 & 2.04 & 2.97 & 4.36 \\
\hline & & Pseudomonas & 10 & 37 & 21 & 46.5 & 2.10 & 2.08 & 2.86 & 3.79 \\
\hline \multirow[t]{3}{*}{ RS3-73 } & 45 & base line & & 31 & 13 & 10.2 & 2.48 & 2.44 & 2.75 & 4.23 \\
\hline & & increased $P_{m v}$ & & 41 & 27 & 15.7 & 2.34 & 2.24 & 2.83 & 4.53 \\
\hline & & Pseudomonas & 5.0 & 40 & 7 & 41.4 & 1.64 & 1.61 & 2.29 & 3.42 \\
\hline \multirow[t]{3}{*}{ Mean \pm SEM } & $42 \pm 3$ & base line & & $30 \pm 2$ & $12 \pm 1$ & $8.3 \pm 0.9$ & $2.43 \pm 0.10$ & $2.26 \pm 0.17$ & $2.71 \pm 0.11$ & $4.02 \pm 0.18$ \\
\hline & & increased $P_{m v}$ & & $42 \pm 2$ & $28 \pm 2$ & $15.0 \pm 1.2$ & $2.06 \pm 0.14$ & $1.60 \pm 0.17$ & $2.78 \pm 0.11$ & $4.16 \pm 0.20$ \\
\hline & & Pseudomonas & $12.8 \pm 4.3$ & $44 \pm 3$ & $10 \pm 2$ & $53.7 \pm 7.7$ & $1.83 \pm 0.22$ & $1.60 \pm 0.22$ & $2.41 \pm 0.14$ & $3.33 \pm 0.17$ \\
\hline
\end{tabular}

Base line values are means for all studies. Each value in the table is an average of values obtained over at least two hours of steady state.

* $\mathrm{P}_{\mathrm{ps}}$ and $\mathrm{P}_{\mathrm{la}}$; average pulmonary artery and left atrial pressures, respectively, relative to bottom of the lung.

$\ddagger$ Q̀lym; lung lymph flow.

$\$$ alb. and glob.; albumin and globulin concentrations, respectively.

$\| \mathbf{P}_{\mathbf{m v}}$; pulmonary microvascular pressure.

(a) After at least $2 \mathrm{~h}$ of base-line observation of lymph flow, vascular pressures and lymph and plasma protein concentrations, we inflated the pulmonary artery cuff, increasing right atrial pressure by $7-10 \mathrm{~cm} \mathrm{H}_{2} \mathrm{O}$ for $60-90$ min. This caused the animals no distress, but usually resulted in a slight decrease in aortic, pulmonary arterial, and left atrial pressures.

(b) After at least $2 \mathrm{~h}$ of base-line observation of lymph flow, vascular pressures, and lymph and plasma protein concentrations, we inflated the left atrial balloon, increasing left atrial and pulmonary artery pressures. We kept pressures stable for at least $4 \mathrm{~h}$; all measured variables were constant for the last $2 \mathrm{~h}$ of each study.

(c) After at least $2 \mathrm{~h}$ of base-line observation of lymph flow, vascular pressures, and lymph and plasma protein concentrations, we infused $10^{5}-10^{10}$ Pseudomonas aeruginosa organisms suspended in $100-500 \mathrm{ml}$ of $0.9 \%$ sodium chloride through the right atrial catheter over $30-90 \mathrm{~min}$. We made the bacterial suspensions from fresh blood agar subcultures obtained from the clinical laboratory of the University of California Hospital and determined the live dose by colony counts of serial dilutions of each suspension. This is an estimate of the minimum number of organisms infused, since nonviable organisms would not be counted. We observed the animals continuously until pressures and lymph flow were stable for at least $2 \mathrm{~h}$ (the total period of constant observation was 6-12 h), and intermittently until pressures and lymph flow returned to base line.

\section{RESULTS}

We successfully maintained the chronic pulmonary lymph fistulas in seven of the nine animals.

\section{Test for the presence of systemic lymph}

We inflated the pulmonary arterial cuff in six of the seven animals to elevate right atrial pressures by 7-10 $\mathrm{cm} \mathrm{H}_{2} \mathrm{O}$ while keeping pulmonary microvascular pressure at or below base-line levels. Since increased systemic venous pressure increases systemic lymph flow (17), if lymph flow increased while right atrial pressure was high, we concluded that there was significant contamination by systemic lymph. This was not true for any 
TABLE II

Responses of Unanesthetized Sheep to Pseudomonas Bacteremia

\begin{tabular}{lcccc}
\hline & $n$ observations & Base line & $\begin{array}{c}\text { Initial* } \\
\text { response }\end{array}$ & $\begin{array}{c}\text { Delayed } \\
\text { response }\end{array}$ \\
\hline Cardiac output $\$ \mathrm{ml} /(\mathrm{min} \times \mathrm{kg})$ & $7 / 5$ & $140 \pm 10$ & $140 \pm 10$ & $150 \pm 10$ \\
Arterial $\mathrm{P}_{\mathrm{O}_{2}}$, torr & $10 / 8$ & $99 \pm 1$ & $86 \pm 3 \|$ & $96 \pm 4$ \\
Arterial $\mathrm{P}_{\mathrm{CO}}$, torr & $10 / 8$ & $40 \pm 1$ & $40 \pm 1$ & $37 \pm 1 \|$ \\
Arterial $\mathrm{pH}$ & $10 / 8$ & $7.46 \pm 0.01$ & $7.46 \pm 0.01$ & $7.46 \pm 0.02$ \\
White blood cell count $10^{3} / \mathrm{mm}^{3}$ & $8 / 7$ & $10.3 \pm 0.9$ & $4.3 \pm 0.6 \|$ & $7.2 \pm 1.6$ \\
Blood platelet count, $10^{5} / \mathrm{mm}^{3}$ & $7 / 7$ & $7.4 \pm 1.1$ & $7.0 \pm 1.2$ & $3.9 \pm 0.6 \|$ \\
Indicator dilution $\$$ quantity of lung water, $\mathrm{ml} / \mathrm{kg}$ & $6 / 5$ & $6.6 \pm 1.0$ & $5.9 \pm 1.0$ & $7.4 \pm 1.0$ \\
\hline
\end{tabular}

All values are mean $\pm \mathrm{SEM}$.

* Initial response measurements were made at the time of peak pulmonary artery pressure, 45-90 min after beginning Pseudomonas infusion.

¥Delayed response measurements were made after at least $2 \mathrm{~h}$ of steady state during the period of highest lymph flow, 5-8 $\mathrm{h}$ after beginning Pseudomonas infusion.

$\$$ These measurements were not made in the two sheep which died of pulmonary edema.

I| Values differed significantly from base line, $P<0.05$.

of the animals tested in this study. We could not test one animal (RS3-73) because the cuff was defective.

Response to increased pulmonary microvascular pressure

We inflated the left atrial balloon once in each of the seven animals. The results are summarized in Table $\mathrm{I}$. When pressure was elevated, lymph flow increased, approximately doubling for a $15-\mathrm{cm} \mathrm{H}_{2} \mathrm{O}$ increase in pressure. Lymph-plasma protein concentration ratios always fell from base line during increased pressure. We did not elevate pressures high enough to cause overt pulmonary edema because we wanted steady state observations.

\section{Response to Pseudomonas infusion}

General. We infused Pseudomonas 18 times in seven sheep. The pattern of response was stereotyped. The initial response began 30-60 min after starting the infusion. The sheep developed chills, fever, and tachypnea; pulmonary artery pressure rose, left atrial pressure fell, and aortic pulse pressure widened, with mean pressure slightly higher than base line. Lymph flow increased. After 1-3 h, tachypnea was gone, pulmonary artery pressure was stable (slightly higher than base line), temperature was usually normal, systemic arterial pressure was near base line, and the animals appeared well.

3-5 $\mathrm{h}$ after initial bacteremia, lung lymph flow increased further while other measured variables were stable. Two animals died of pulmonary edema 7 (S32-72) and $9 \mathrm{~h}$ (S30-72) after Pseudomonas was given, but all other animals recovered to base-line pressures and lymph flows in 24-72 h.

In several experiments, we made repeated measurements of lung water by indicator dilution and of arterial blood gases, and peripheral blood white cell and platelet counts. These are summarized in Table II. Cardiac output, lung water, and arterial $\mathrm{pH}$ did not change significantly from base line. Arterial Poz decreased 13 torr $(P<0.01)$ during the initial response and returned to base line during the delayed response. Arterial $\mathrm{PCO}_{2}$ was slightly decreased during the delayed response (mean, 3 torr below base line, $P<0.02$ ). Peripheral blood white cell counts fell dramatically during the initial response but were increasing toward base line during the second phase; platelet counts were depressed during the delayed phase.

Lymph flow and protein content. Fig. 1 illustrates the response of vascular pressures, lung lymph flow, and lymph-plasma protein concentration ratios to a Pseudomonas infusion. Although the magnitude of pressure and lymph flow response differed among animals and with different doses of organisms, we saw qualitatively similar responses in all 18 studies. About $45 \mathrm{~min}$ after the beginning of the infusion, systemic arterial pulse pressure widened and pulmonary artery pressure rose. Slightly later, lung lymph flow increased and lymph plasma (L/P) albumin and globulin ratios decreased. As vascular pressures returned toward base line, lymph flow decreased and L/P protein ratios rose.

Several hours after Pseudomonas, there was a large increase in lung lymph flow while $\mathrm{L} / \mathrm{P}$ ratios remained high. Lymph flow finally stabilized for several hours, then decreased gradually to base line over $24-72 \mathrm{~h}$. Five sheep received 16 separate infusions and appeared well during the period of highest lymph flow; two sheep died of pulmonary edema after a single infusion.

Lung lymph flow, vascular pressures, and lymph and plasma albumin and globulin concentrations during the steady state delayed response period are listed in $\mathrm{Ta}$ - 


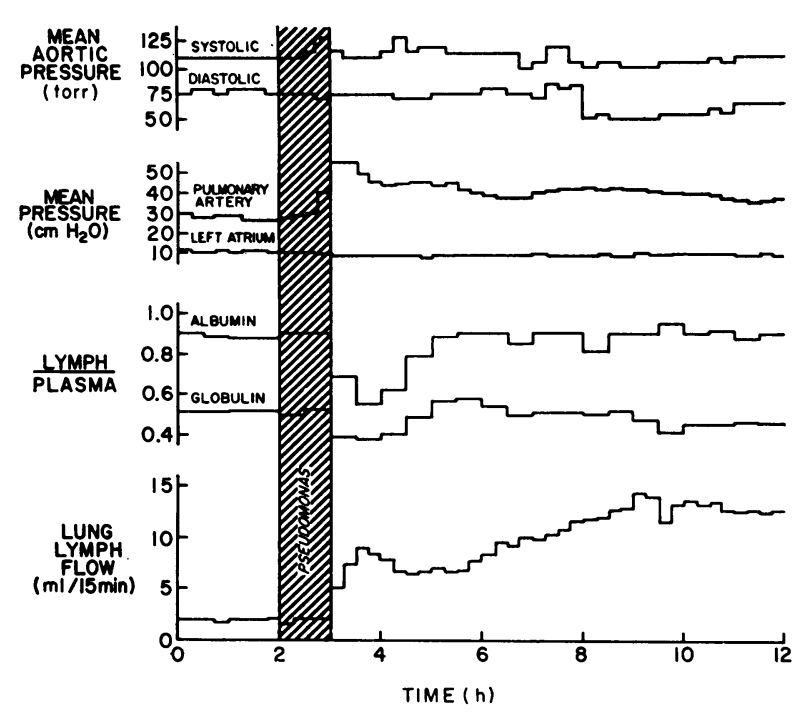

FIGURE 1 Response of lung lymph flow, lymph-plasma protein concentration ratios, and vascular pressures to a Pseudomonas infusion. Pressures are averaged over 15-min intervals, lymph flow is shown for each $15 \mathrm{~min}$ and protein ratios are for each $30 \mathrm{~min}$. After a stable base-line period, we infused Pseudomonas into the right atrium. $45 \mathrm{~min}$ after the start of the infusion, pulmonary artery (PA) pressure rose and systemic arterial pulse pressure widened. This was followed by an increase in lymph flow and decrease in lymph-plasma protein ratios. The initial increase in PA pressure was transient and as the pressure returned toward base line, lymph flow decreased and protein ratios rose to near base-line levels. Beginning $3 \mathrm{~h}$ after the Pseudomonas, there was a large increase in lymph flow while protein ratios and pulmonary vascular pressures remained stable. Lymph flow reached a plateau for several hours. All of the variables returned to base-line levels after $48 \mathrm{~h}$.

ble I for a single Pseudomonas study in each of the seven sheep. In Table III are listed the data for the four sheep which received more than one Pseudomonas infusion. Fig. 2 compares the steady state response of lung lymph flow and pulmonary microvascular pressure to inflation of the left atrial balloon with the response to one Pseudomonas infusion in each of the animals. After Pseudomonas infusion, pressure was usually slightly elevated, but lymph flow was much higher than that resulting from increased pressure alone.

Steady state lung lymph protein flows, calculated as the product of lymph flow and lymph protein concentration, are shown as a function of microvascular pressure in Fig. 3. When pressure is increased mechanically, lymph flow increases, but lymph protein concentration always falls and lymph protein flow changes very little. After Pseudomonas infusion, lymph protein concentrations are much higher than when lymph flow is increased by increasing pressure, so that lymph protein flow is consistently higher than that resulting from elevated pressure.
Additional studies. To confirm that increased lymph flow represented increased filtration from lung vessels, we manipulated pulmonary vascular pressure during the period of high lymph flow after Pseudomonas. Fig. 4 shows lung lymph flow and microvascular pressure in one such experiment. With lymph flow two and a half times base line, we raised left atrial pressure $10 \mathrm{~cm} \mathrm{H}_{2} \mathrm{O}$. Lymph flow rapidly increased and the animal appeared to be in respiratory distress, necessitating deflation of the balloon after only 7 min. Later we decreased pulmonary vascular pressure for $45 \mathrm{~min}$ by inflating the pulmonary artery cuff. This decreased lymph flow, which returned towards its elevated level after the cuff was deflated. We did the last part of this experiment in all but one animal (RS3-73) and saw similar responses in each. We increased left atrial pressure during high lymph flow in only the one animal because we were afraid of causing alveolar flooding and death.

We killed the nine sheep 1-9 $\mathrm{h}$ after a Pseudomonas infusion and measured extravascular lung water. The ratios of extravascular lung water to dry weight of bloodless lung ( $Q w 1 / d Q 1)$ are listed in Table IV along with the mean and SD for 13 normal sheep. The two

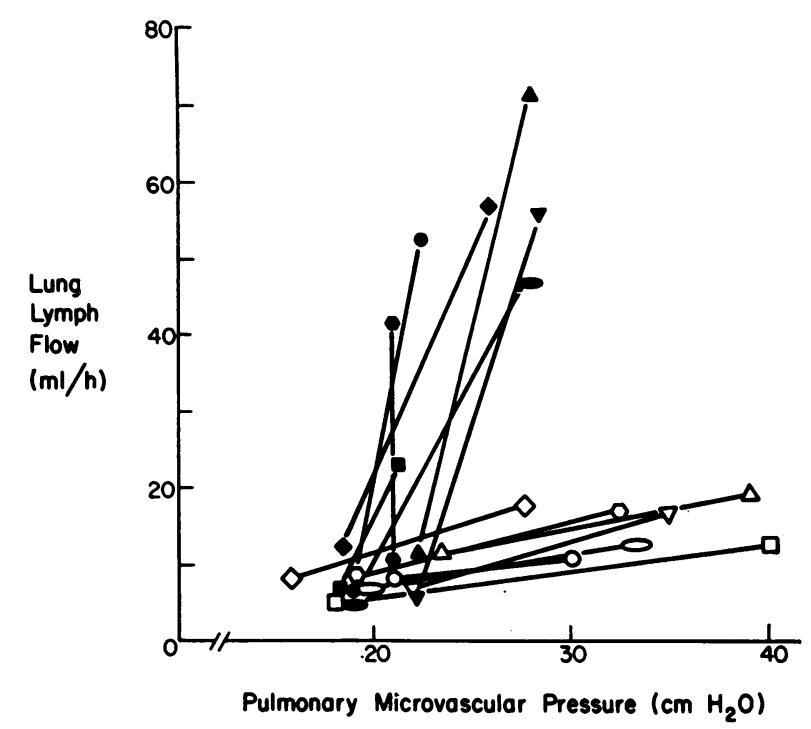

FIGURE 2 Steady state response of lung lymph flow to mechanically increased pulmonary microvascular pressure (see text) and to a Pseudomonas infusion in seven sheep. Different-shaped symbols are used for each of the animals. Open symbols are studies where pressure was increased mechanically. Closed symbols are Pseudomonas studies. Lines connect base-line and experimental observations in a single experiment. Each point is an average of at least $2 \mathrm{~h}$ of steady state. All experimental observations after Pseudomonas are from the steady state delayed response period. After Pseudomonas bacteremia, lymph flow is much higher than would be expected on the basis of increased pressure alone. 
animals that died of pulmonary edema had gross edema at death and their postmortem lung water content was high. Only one other animal (RS3-73) had distinctly elevated lung water at death, $6 \mathrm{~h}$ after Pseudomonas.

Both fresh frozen and fixed sections from the lungs of the nine sheep showed peribronchial and perivascular fluid cuffs to varying degrees. The amount of interstitial edema did not correlate with the time after Pseudomonas when the animal was killed. Only the two animals that died of pulmonary edema had any histologic evidence of alveolar flooding. Large dilated lymphatics were commonly observed. The histological findings in one sheep are illustrated in Fig. 5.

\section{DISCUSSION}

Under steady state conditions, lymph flow from an organ reflects net fluid filtration from the organ's exchanging vessels (18-20). In addition, lymph protein content does not change during transit across lymph nodes (21) or through peripheral lymphatics $(18,21)$, and several investigators have taken steady state lymph protein concentration to represent protein concentration in net microvascular filtrate $(18,19)$.

Our studies show that after Pseudomonas bacteremia in awake sheep, a prolonged period of apparent steady state develops, during which net transvascular fluid and protein movement in the lung, as reflected in lung lymph, is increased out of proportion to that shown to result from increased vascular pressure alone in the same ani-

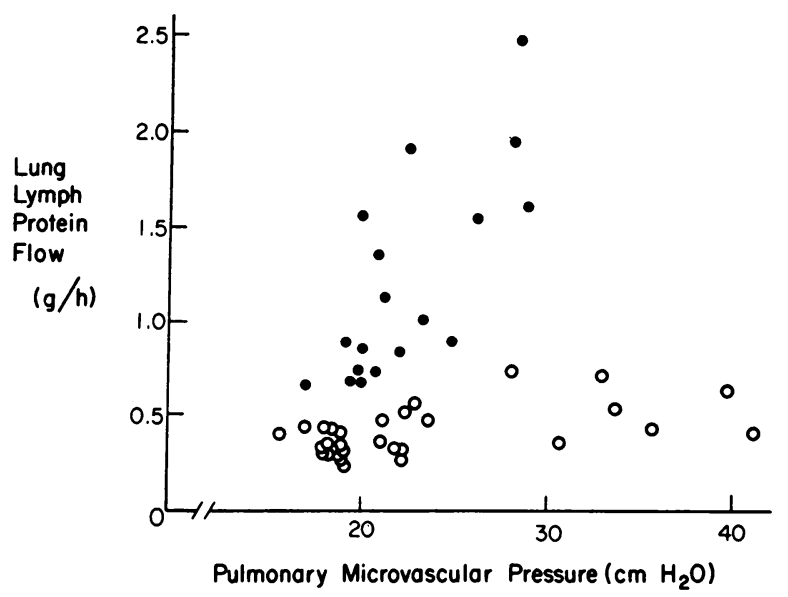

FIGURE 3 Steady state lung lymph protein flow (lymph flow $\times$ lymph protein concentration) as a function of pulmonary microvascular pressure for all of the studies. Open circles include base-line values for each experiment and experimental observations with mechanically increased pressure (see text). Closed circles are studies after Pseudomonas. Each point is averaged over at least $2 \mathrm{~h}$ of steady state. Lymph protein flow after Pseudomonas was always higher than expected on the basis of increased pressure alone.

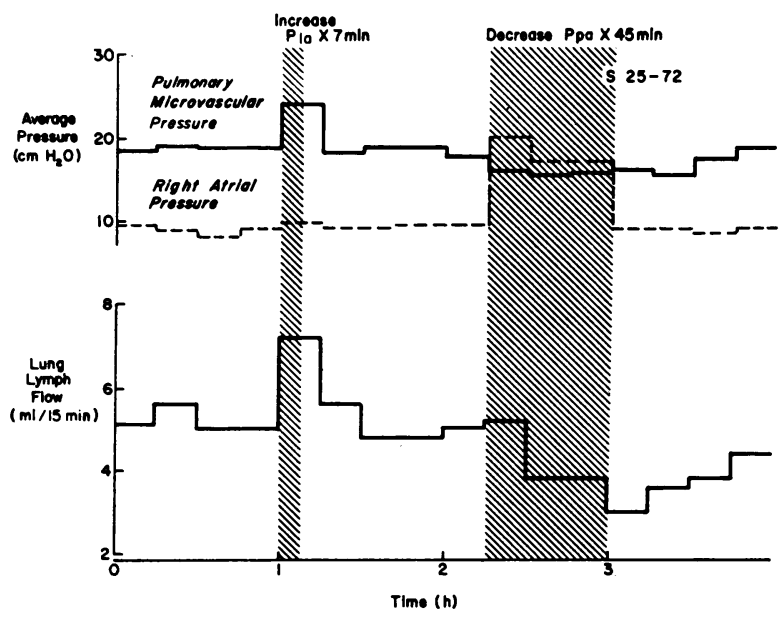

Figure 4 Response of lung lymph flow to changes in pulmonary vascular pressure during steady state increased permeability after Pseudomonas infusion. Base-line lymph flow was $2 \mathrm{ml} / 15 \mathrm{~min}$. With lymph flow stable at about two and a half times base line, a balloon was inflated in the left atrium increasing pulmonary microvascular pressure. Lymph flow immediately increased, and after about 7 min, the animal developed severe respiratory distress. The balloon was deflated, pressure returned to base line (pressure in the graph is averaged over 15-min intervals), distress subsided, and lymph flow decreased. Later, a cuff was inflated around the main pulmonary artery, decreasing pulmonary microvascular pressure (while right atrial pressure increased), and lymph flow fell, returning to original levels as pulmonary pressure returned when the cuff was deflated.

mal. This indicates that the resistance of walls of permeable vessels to the movement of fluid and protein is decreased (increased permeability). The changes were completely reversible in five of seven sheep.

Effects of Pseudomonas bacteremia on lung protein and fluid filtration are clearly different from the effects of increased vascular pressure alone. When pressure is increased, lymph flow increases, but lymph protein concentration always falls and net protein flux increases only slightly. After Pseudomonas, lymph-plasma protein concentration ratios may fall slightly from base line if pressure is elevated, but lymph flow and lymph protein flow are always much higher than with increased pressure alone. The effect of increasing left atrial pressure while permeability is increased was dramatically demonstrated in one animal (Fig. 4), which almost died after a brief, moderate elevation in pressure.

The effects of Pseudomonas on lung lymph cannot be adequately accounted for either by hemodynamic changes or by postulating a special mechanism for fluid and protein exchange across lymphatic vessels. Some interstitial fluid could have accumulated during the initial transient period of increased pressure, but the total 
TABLE III

Steady_State Response of Lung Lymph Flow and Lymph and Plasma Protein Concentrations to Multiple Pseudomonas Infusions in Four Sheep

\begin{tabular}{|c|c|c|c|c|c|c|c|c|c|}
\hline \multirow{3}{*}{ Sheep no. } & \multirow{3}{*}{ Conditions } & \multirow{3}{*}{$\begin{array}{l}\text { Pseudomonas } \\
\text { dose }\end{array}$} & \multirow{3}{*}{$P_{p: 2} *$} & \multirow{3}{*}{$P_{1: 2} *$} & \multirow{3}{*}{$\dot{Q}_{1 \mathrm{yn},} *$} & \multicolumn{4}{|c|}{ Protein } \\
\hline & & & & & & \multicolumn{2}{|c|}{ Lymph } & \multicolumn{2}{|c|}{ Plasma } \\
\hline & & & & & & & & & \\
\hline & & $\times 10^{8}$ & \multicolumn{2}{|c|}{$\mathrm{cm} \mathrm{H}_{2} \mathrm{O}$} & $m l / h$ & \multicolumn{4}{|c|}{$\mathrm{g} / 100 \mathrm{ml}$} \\
\hline \multirow[t]{6}{*}{ S26-72 } & base line & & 27 & 11 & 5.8 & 2.51 & 2.62 & 2.64 & 4.06 \\
\hline & Pseudomonas & 0.5 & 32 & 10 & 15.2 & 2.25 & 2.32 & 2.52 & 3.32 \\
\hline & Pseudomonas & 6.0 & 29 & 13 & 15.4 & 2.27 & 3.29 & 2.29 & 4.43 \\
\hline & Pseudomonas & 10 & 31 & 10 & 18.1 & 2.26 & 2.66 & 2.51 & 3.70 \\
\hline & Pseudomonas & 10 & 34 & 9 & 15.0 & 2.49 & 2.40 & 2.51 & 3.45 \\
\hline & Pseudomonas & 32 & 35 & 11 & 22.9 & 2.32 & 2.60 & 2.60 & 3.63 \\
\hline \multirow[t]{6}{*}{$\mathrm{S} 36-72$} & base line & & 25 & 10 & 10.4 & 2.14 & 2.18 & 2.45 & 4.42 \\
\hline & Pseudomonas & 1.0 & 35 & 13 & 21.2 & 1.81 & 2.12 & 2.52 & 4.03 \\
\hline & Pseudomonas & 5.0 & 28 & 9 & 16.0 & 1.95 & 2.14 & 2.37 & 4.40 \\
\hline & Pseudomonas & 15 & 36 & 13 & 29.6 & 1.66 & 1.92 & 2.30 & 3.94 \\
\hline & Pseudomonas & 22 & 48 & 10 & 57.0 & 1.37 & 1.34 & 2.28 & 3.62 \\
\hline & Pseudomonas & 25 & 43 & 6 & 85.3 & 0.72 & 0.92 & 1.76 & 2.84 \\
\hline \multirow[t]{4}{*}{ RS2-73 } & base line & & 31 & 11 & 6.4 & 2.76 & 2.39 & 2.98 & 4.19 \\
\hline & Pseudomonas & 1.0 & 33 & 10 & 16.0 & 2.20 & 2.02 & 2.56 & 3.86 \\
\hline & Pseudomonas & 40 & 37 & 21 & 46.5 & 2.10 & 2.08 & 2.86 & 3.79 \\
\hline & Pseudomonas & 900 & 37 & 9 & 15.7 & 2.50 & 2.02 & 2.82 & 4.02 \\
\hline \multirow[t]{3}{*}{ RS3-73 } & base line & & 31 & 13 & 10.2 & 2.48 & 2.44 & 2.75 & 4.23 \\
\hline & Pseudomonas & 5.0 & 40 & 7 & 41.4 & 1.64 & 1.61 & 2.29 & 3.42 \\
\hline & Pseudomonas & 7.5 & 36 & 17 & 20.2 & 2.22 & 2.16 & 2.46 & 3.68 \\
\hline
\end{tabular}

Base line values are means of base line for all studies. Each value in the table is an average of values obtained over at least $2 \mathrm{~h}$ of steady state.

* See Table I footnote for explanation of abbreviations.

amount of lymph in excess of base line during the 24-72-h reaction exceeded $1,000 \mathrm{ml}$ in some experiments, and the sheep lung's tissue cannot possibly store that much fluid. Also, neither indicator dilution nor postmortem extravascular lung water measurements suggested significant water accumulation during the early phase. The 3-10-fold plateau lymph flow increase after Pseudomonas was much higher than that resulting from increased pressure, even if pulmonary artery pressure is taken as the best estimate of pressure in exchanging vessels (the highest possible value). Although some unknown mechanism for concentration of protein in lymphatics could keep lymph-plasma ratios near base-line levels, this is not what happened when lymph flow increased in response to elevated pressure in the same animals that received Pseudomonas.

Steady state lymph flow and protein concentrations have been used to estimate porosity of exchanging vessel walls in the lung (19) and other organs (18). We describe such a model for the sheep lung based on our data in the appendix. Although Shirley, Wolfram, Wasserman, and Mayerson (22) and more recently Pietra,
Szidon, Leventhal, and Fishman (23) have suggested that pore size may increase with increased vascular pressure, and Arturson, Groth, and Grotte suggested that increased pressure decreases pore size (24), we did not find either change necessary to predict the effects of increased pressure on lymph-plasma protein ratios. We found that a fixed vascular membrane structure with a large number of small pores, which completely exclude albumin per one intermediate pore of $125 \AA$ radius, would predict experimentally measured lymphplasma albumin and globulin concentration ratios over a wide range of microvascular pressures (25). Steady state lymph flow and lymph-plasma protein ratios after Pseudomonas could not be predicted from the model either by increasing the intermediate pore radius or by introducing large leaks (1,000 $\AA$ radius), but when intermediate pore radius was increased to $150 \AA$ and small pore area was approximately doubled, the model predicted results from Pseudomonas experiments reasonably well. Thus, large changes in fluid and protein filtration may result from small changes in the structure of exchanging vessels. 
TABLE IV

Extravascular Lung Water at Time of Death after Pseudomonas Bacteremia in Nine Sheep

\begin{tabular}{cccccc}
\hline Sheep no. & $\begin{array}{c}\text { Body } \\
\text { weight }\end{array}$ & $\begin{array}{c}\text { Pseudomonas } \\
\text { dose }\end{array}$ & $\begin{array}{c}\text { Time after } \\
\text { Pseudomonas }\end{array}$ & $\begin{array}{c}\text { Apparent clinical } \\
\text { condition }\end{array}$ & Qwl/dQ1* \\
\hline S25-72 & $k g$ & $\times 10^{8}$ & $h$ & & \\
S26-72 & 31.5 & 0.01 & 3.5 & well & 3.71 \\
S28-72 & 44.0 & 10.0 & 6.0 & well & 4.08 \\
S29-72 & 53.0 & 5.0 & 5.0 & well & 4.07 \\
S30-72 & 44.0 & 1.0 & 1.0 & fever, tachypnea & 4.49 \\
S32-72 & 37.5 & 7.5 & 9.0 & dying & 6.28 \\
S36-72 & 34.0 & 0.10 & 7.0 & dying & 7.11 \\
RS2-73 & 49.0 & 25.0 & 6.0 & well & 4.16 \\
RS3-73 & 51.0 & 10.0 & 5.5 & well & 4.13 \\
Normal sheep, $n=13$, & 45.0 & 20.0 & 6.0 & & 5.16 \\
mean \pm SD & & & & & $4.05 \pm 0.30$ \\
\hline
\end{tabular}

* Ratio of extravascular lung water (Qwl) to dry weight of bloodless lung (dQl).

$\ddagger$ No lymph studies done in these sheep because lymph cannulas clotted.

Morphological evidence of changes in capillary endothelium in the lung consistent with increased permeability is conflicting. Cottrell et al. saw disintegration of endothelium during alloxan edema in dogs (26), and Cunningham and Hurley saw bleb formation and endothelial gaps after alphanapthylthiourea in dogs (27). However, Hovig, Nicolaysen, and Nicolaysen reported normal endothelium in rabbit lungs when permeability was high after depletion of $\mathrm{Ca}^{++}$and $\mathrm{Mg}^{++}$(28), and a recent study of ozone-induced pulmonary edema in monkeys shows no changes by transmission electron microscopy but modest widening ("unzipping") of interendothelial junctions by freeze-fracture electron microscopy (29). The effects of Pseudomonas predicted by our model would probably not be visible by routine electron microscopy.

The concept that large changes in filtration may result from small changes in the structure of exchanging vessels is consistent with our observations that the lesion caused by Pseudomonas is entirely reversible in most sheep, and suggests that severe edema in humans occurring in the absence of heart failure may not necessarily be the result of extensive, irreversible damage to the lung's vascular endothelium.

The role of lung lymphatics in protecting against pulmonary edema has been suggested $(19,20,30)$, but not generally appreciated (31). Our studies show that lung lymphatics in awake sheep have the capacity to clear large quantities of filtered fluid (up to $85 \mathrm{ml} / \mathrm{h}$ in animal S36-72) and protein. If vascular damage is severe enough or if pressure is high while permeability is increased (as in our two sheep that died of pulmonary edema), lymphatic pumping capacity may be exceeded and fluid may accumulate. It may be important to maintain low vascular pressures in clinical situations where increased lung vascular permeability is suspected. We saw large increases in lymph flow in several studies with little water accumulation, demonstrating that the lymphatic system is sensitive to increased fluid filtration.

Respiratory distress developing in patients with gramnegative sepsis has been attributed to increased permeability of lung microvessels $(2,32)$, and $E$. coli endotoxin increases permeability in canine abdominal viscera (33) and increases the indicator dilution quantity of water in the lungs of anesthetized dogs (34). A commercial Pseudomonas endotoxin preparation causes transient pulmonary arterial hypertension in small doses in calves (35). We do not know whether the response we are seeing in sheep is due entirely to endotoxin or whether some other component of the organisms is also involved. We did not see systemic hypotension characteristic of the canine endotoxin reaction, but this could be due to differences between animal species and between endotoxins from different organisms.

We were unable to demonstrate a consistent doseresponse relationship either among different animals or in a single animal. This may have resulted in part from varying numbers of dead or clumped organisms in the suspensions, making the colony count an inaccurate estimate of dose. Sequential studies in the same animal have the possible additional problem of development of tolerance (36).

Because the response we observed was delayed from the time of beginning the infusion, we think it probably was not a direct effect of the organisms, but rather was mediated by some biologically active substance. There are several known mediator substances that could be involved (37-39), but further studies are necessary before we can make rational suggestions. Whether the same biochemical mechanisms are involved in the initial 


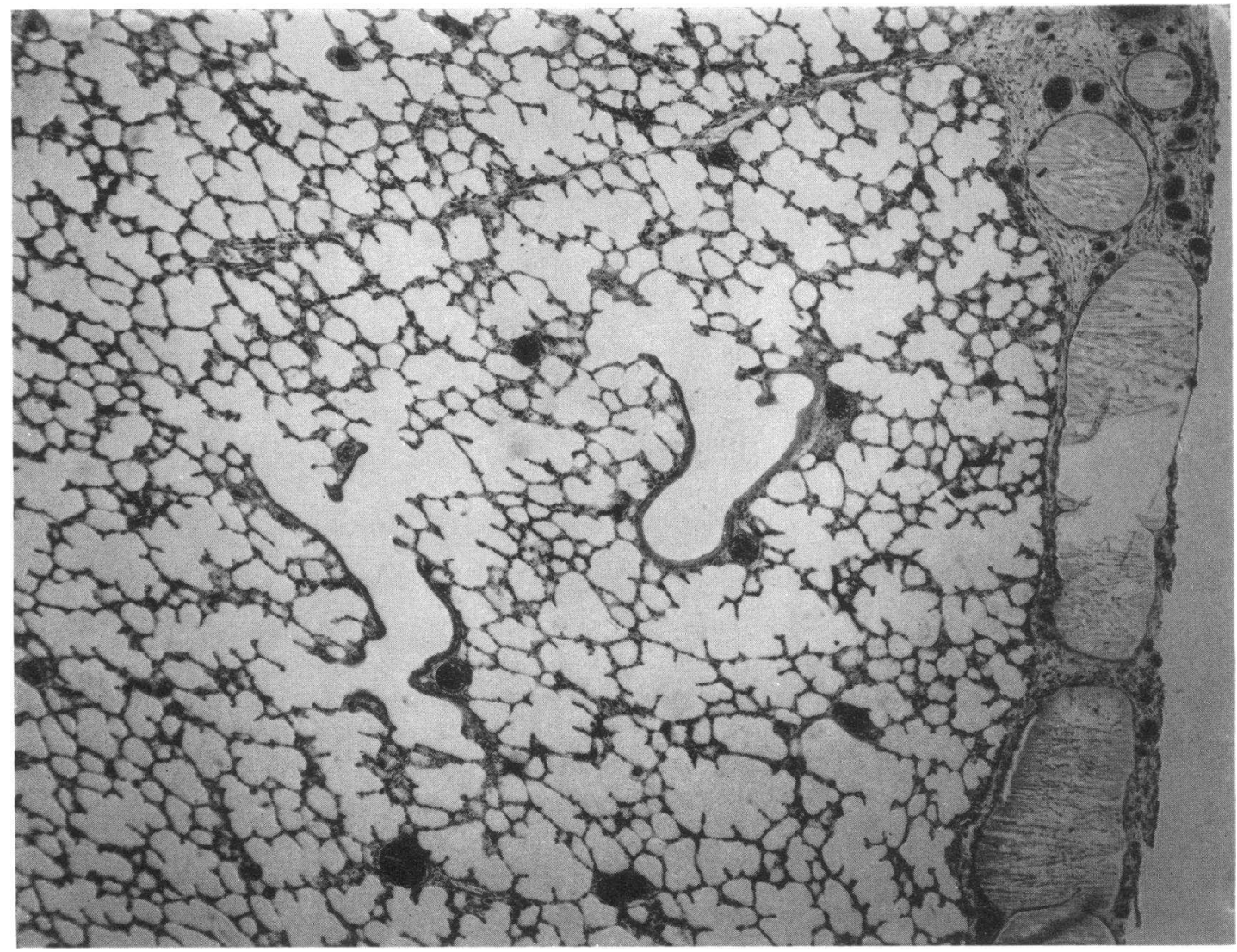

FIGURE 5 Photomicrograph of a $10-\mu \mathrm{m}$ thick histological section from the lung of sheep S36-72 killed $6 \mathrm{~h}$ after a Pseudomonas infusion. Biopsy from posterior basilar segment of right lower lobe was quick frozen and prepared by method of Storey and Staub (13). Magnification $\times 25$. The animal appeared well but lung lymph flow at death was $85.3 \mathrm{ml} / \mathrm{h}$. Postmortem extravascular lung water content was normal. There is slight widening of an interlobular septum and slight perivascular cuffing, but the most striking histological finding is marked dilation of the subpleural lymphatics. There is no alveolar edema.

and delayed responses and whether the two phases are independent or interdependent also remains to be established. We are very interested in observing the effects of other microvascular toxins in our preparation to establish whether the pattern of response is similar, thus suggesting a "final common pathway" for toxic vascular injuries.

In addition to demonstrating that Pseudomonas bacteremia predictably causes increased pulmonary vascular permeability to protein, that the lung lymphatics have a large capacity to pump excess filtered fluid and protein, and that the lung lymphatic system is very sensitive to increases in fluid filtration, we have described a good model for experimental studies of vascular permeability in the lung. Since the changes produced are reversible, repeated studies can be done in a single animal. The long period of steady state will be particularly useful in studying the ability of various physical and pharmacological agents to reverse the response.

\section{APPENDIX}

Changes due to increased permeability in an equivalent pore model of sheep lung exchanging vessels. We developed an equivalent-pore model of sheep lung exchanging vessels, which predicts lymph-plasma albumin and globulin concentration ratios both under base-line conditions and during steady state increased lung vascular pressure (25), and determined the changes in membrane porosity necessary to predict steady state results after Pseudomonas bacteremia.

We used standard thermodynamic flux equations to describe fluid and solute transport (40):

$$
J_{t}=L_{f}\left[\left(\mathrm{P}_{\mathrm{mv}}-\mathrm{P}_{\mathrm{pmv}}\right)-\sigma\left(\Pi_{\mathrm{mv}}-\Pi_{\mathrm{pmv}}\right)\right],
$$

where $J_{f}$ is net fluid flow, $L_{f}$ is membrane fluid conduc- 
tance, $\mathrm{P}_{\mathrm{mv}}$ and $\mathrm{P}_{\mathrm{pur}}$ are mean hydrostatic pressures inside and outside exchanging vessels, respectively, $\sigma$ is the solute reflection coefficient, and $\Pi_{m v}$ and $\Pi_{p m v}$ are osmotic pressures inside and outside exchanging vessels, respectively.

$$
J_{s}=\omega\left(\Pi_{\mathrm{mv}}-\Pi_{\mathrm{pmv}}\right)_{s}+\left(1-\sigma_{s}\right) C_{s} J_{t},
$$

where $J_{\text {o }}$ is net solute flow, $\left(\Pi_{\mathrm{mv}}-\Pi_{\mathrm{pm} v}\right)$, is the transmural osmotic potential for solute $s, \omega$ is the diffusional permeability, $\left(1-\sigma_{s}\right)$ is the sieving coefficient and $C_{s}$ is the mean solute concentration across the membrane.

We wrote the flux equations as functions of the transport coefficients, $L_{f}$ (fluid conductance), $\sigma_{s}$ (reflection coefficient), and $\omega_{s}$ (diffusional permeability) and calculated these coefficients for albumin (assumed molecular radius $=36 \AA$ ) and globulin (assumed molecular radius $=52 \AA$ ) for each pore size by the equations of Kedem and Katchalsky (40).

To get estimates of lymph flow and lymph-plasma albumin and globulin concentration ratios for the whole lung, we made the following assumptions: $(a)$ hydrostatic pressure around exchanging vessels equals zero and remains constant; (b) hydrostatic pressure inside exchanging vessels at the plane of the left atrium equals left atrial pressure plus 0.4 of the difference between pulmonary artery and left atrial pressures (9), and pressure in exchanging vessels in the rest of the lung is a linear function of lung height (zone III lung) (41); (c) pore length $(0.5 \mu \mathrm{m})$ and number of pores per unit filtering membrane area are constant; $(d)$ filtering membrane area is constant and is proportional to lung mass; (e) relative distribution of lung mass in the hydrostatic field is similar among sheep and is like that we measured in four sheep $(8) ;(f)$ plasma albumin and globulin concentrations in exchanging vessels equal those measured in peripheral blood plasma; and $(g)$ under steady state conditions, lymph flow equals net microvascular fluid filtration from the portion of the lung drained and lymph and microvascular filtrate albumin and globulin concentrations are equal.

Using mean pulmonary artery and left atrial pressures and peripheral blood plasma albumin and globulin concentrations measured during steady state base-line and experimental periods in awake sheep, we integrated predictions of eqs. 1 and 2 over the whole lung and obtained estimates of lymph flow and lymph albumin and globulin concentrations..$^{3}$ Instead of making further assumptions necessary to estimate absolute lymph flow, we expressed predicted lymph flow during steady state experimental periods relative to predicted lymph flow at

\footnotetext{
3 Because of strong coupling between fluid and solute fluxes, an iterative solution was required, which we did on a digital IBM 360 computer (IBM Corp., Data Processing Div., White Plains, N. Y.).
}

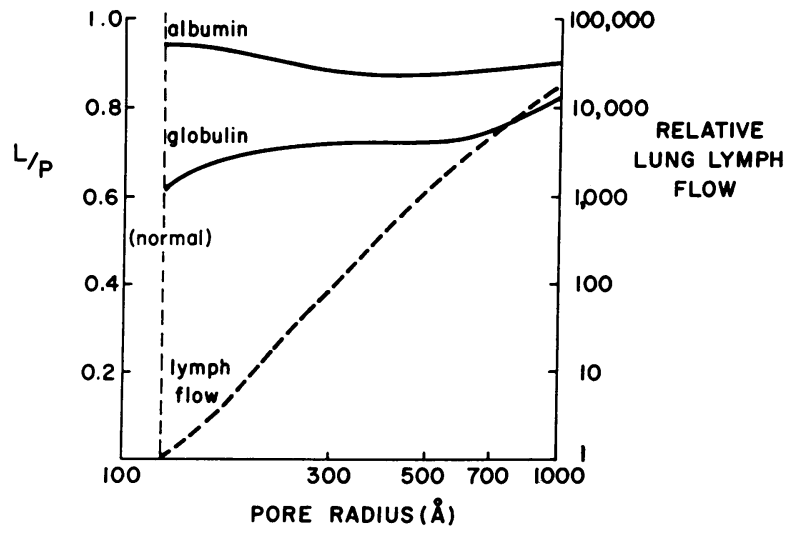

FIGURE $6 \mathrm{~L} / \mathrm{P}$ protein concentration ratios and relative lung lymph flow predicted by our theoretical model as a function of intermediate pore size. Transmural pressure is constant at $21 \mathrm{~cm} \mathrm{H} \mathrm{H}_{2} \mathrm{O}$ at the level of the left atrium (referred to the bottom of the lung). The broken vertical line at a pore radius of $125 \AA$ is the intermediate pore size we determined for normal sheep. Lymph flow at that point is the denominator for relative lung lymph flow (right hand ordinate, log scale). L/P (left hand ordinate, linear scale) for albumin changes only slightly as pore radius increases from $125 \AA$, but globulin L/P rises. Dramatic increases in lymph flow result from small increases in pore radius.

base line in the same experiment (relative lung lymph flow). We manipulated pore sizes and distribution per unit filtering membrane area until we found a model that predicted the experimentally measured lymphplasma albumin and globulin ratios over a range of pulmonary vascular pressures.

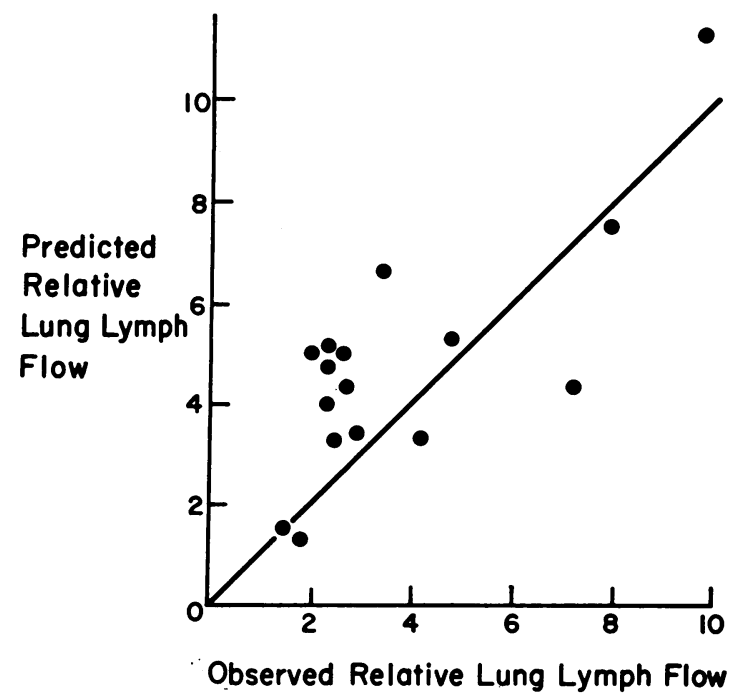

Figure 7 Relative lung lymph flow predicted by our increased permeability model versus the observed steady state values after Pseudomonas bacteremia in 16 studies in five sheep. The line is the line of identity. $r=0.75, P<$ 0.01 . 


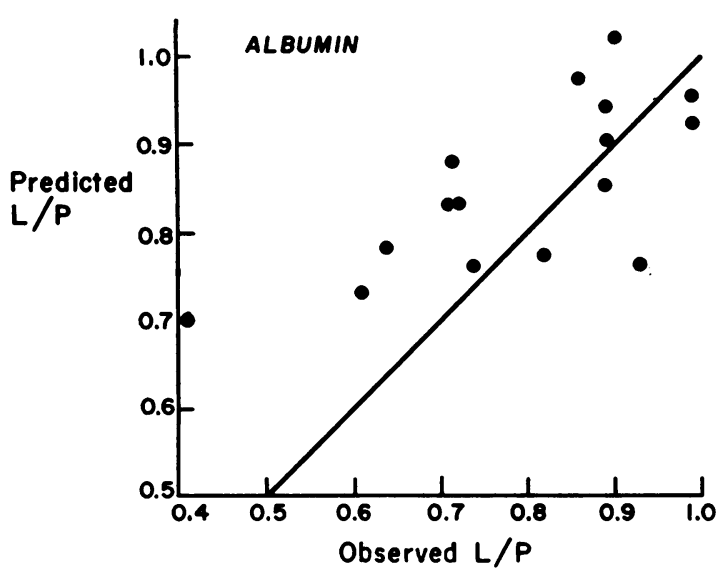

FIGURE 8 L/P albumin concentration ratios predicted by our increased permeability model versus the observed steady state values after Pseudomonas bacteremia in 16 studies in five sheep. The line is the line of identity. $r=0.60, P<$ 0.01 .

To predict the observed lymph-plasma protein ratios over a range of pressures, we had to assume pores of two different diameters, one of small diameter that allows water flow but excludes protein molecules and one of larger diameter that differentially restricts but does not completely exclude the flow of albumin and globulin. Then our objective was to determine the diameters of two different-sized pores and the relative numbers of each required to explain the lymph-plasma protein ratios after Pseudomonas infusions. A model consisting of 1,300 small pores of $20 \AA$ radius ${ }^{4}$ for each larger pore of $125 \AA$ radius satisfactorily predicted observed steady state lymph-plasma albumin and globulin concentration ratios in the control experiments (25).

To estimate the changes in this "normal" model necessary to predict the effects of Pseudomonas bacteremia, we used the 16 experiments in five sheep, during which there were prolonged periods of steady state increased lymph flow with no evidence of alveolar flooding. In these experiments, the hydrostatic pressure change during the period of high lymph flow was small.

Fig. 6 illustrates the effects of increasing intermediate pore radius on relative lung lymph flow and lymphplasma albumin and globulin ratios. The results at $125 \AA$ are for the normal sheep model described above. Changes in lymph-plasma protein ratios as a function of intermediate pore radius result from interaction between diffusive and convective transport for each solute, and this coupling effect initially decreases albumin ratio

4 These pores must be small enough to completely exclude the albumin, the smallest solute we used, with a total area sufficient to account for the fluid flux. We arbitrarily chose the $20 \AA$ value because it is in the range of intercellular tight junction size.

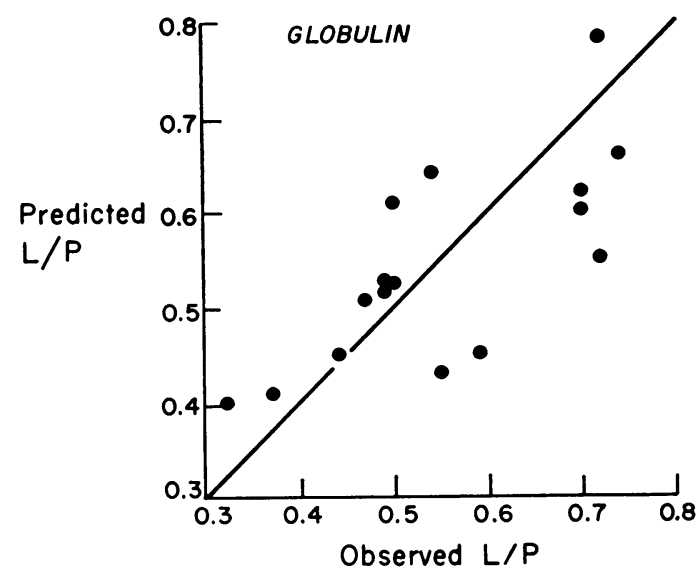

FIGURE $9 \mathrm{~L} / \mathrm{P}$ globulin concentration ratios predicted by our increased permeability model versus the observed steady state values after Pseudomonas bacteremia in 16 studies in five sheep. The line is the line of identity. $r=0.73, P<$ 0.01 .

slightly while increasing the globulin ratio. As pore size becomes larger, the convective limit is approached and both ratios approach unity. Since hydraulic conductance is a function of pore radius to the fourth power, small increases in pore radius have a dramatic effect on predicted lymph flow; a greater than ten-thousandfold increase is predicted for an increase in pore radius to $1,000 \AA$.

The increase in lymph flow in the Pseudomonas experiments was 10 -fold or less and lymph-plasma globulin ratios tended to fall from base line. It has been suggested that for some increased permeability states, the diameter of the larger pores simply increases $(26,38)$. As illustrated by Fig. 6 , increasing the radius of the larger pores to greater than $125 \AA$ or assuming the creation of large leaks (pores of $1,000 \AA$ or more in radius) during Pseudomonas infusions could explain the increases in lymph flow, but lymph-plasma globulin ratios should have increased rather than fallen. However, we could explain the observed changes in both lymph flow and in lymph-plasma globulin ratios that we saw after Pseudomonas if we assume that the radius of the small pores was increased from 20 to $30 \AA^{5}$ and the radius of the larger pores from 125 to $150 \AA$. Figs. 7, 8, and 9 show predicted versus observed values for relative lung lymph flow and lymph-plasma albumin and globulin ratios.

Part of the discrepancy between predicted and observed data may result from our attempt to fit all of

\footnotetext{
'As mentioned before, the small pores can be any size as long as they exclude albumin. The increased permeability model requires that total small pore area be slightly more than doubled. This could be done by increasing either their size or number.
} 
the studies to a single model, even though the degree of permeability change probably was different among animals. Other sources of error may lie in our assumptions, especially the calculation of microvascular pressure and the assumption of constant zero interstitial pressure (42). These factors remain to be worked out in subsequent, more refined modeling and experimental studies.

\section{ACKNOWLEDGMENTS}

The authors appreciate the technical help of Mrs. Elizabeth Schultz and Mr. Abner Mackay.

This work was supported in part by National Heart and Lung Institute Pulmonary SCOR Grant HL14201. Drs. Brigham and Woolverton were supported by Graduate Training Grant HL05251.

\section{REFERENCES}

1. Visscher, M., F. Haddy, and G. Stephens. 1956. The physiology and pharmacology of lung edema. Pharmacol. Rev. 8: 389-434.

2. Robin, E. D., L. C. Carey, A. Grenvick, F. Glauser, and R. Gaudio. 1972. Capillary leak syndrome with pulmonary edema. Arch. Intern. Med. 130: 66-71.

3. Staub, N. C., H. Nagano, and M. L. Pearce. 1967. Pulmonary edema in dogs, especially the sequence of fluid accumulation in lungs. J. Appl. Physiol. 22: 227240.

4. Brigham, K. L., and J. D. Snell, Jr. 1973. In vivo assessment of pulmonary vascular integrity in experimental pulmonary edema. J. Clin. Invest. 52: 2041-2052.

5. Nicolaysen, G. 1971. Increase in capillary filtration rate resulting from reduction in the intravascular calcium ion-concentration. Acta Physiol. Scand. 81: 517-527.

6. Drinker, C. K., and E. Hardenbergh. 1949. Acute effects upon the lungs of dogs of large intravenous doses of alpha-napthyl thiourea (ANTU). Am. J. Physiol. 156: $35-43$.

7. May, N. D. 1970. Anatomy of the Sheep. University of Queensland Press, St. Lucia, Que., Australia. 3rd edition. 75-120.

8. Staub, N. C., and R. Sobel. 1974. Effect of lung mass distribution on microvascular filtration coefficient, Kf. Fed. Proc. 33 : 412 . (Abstr.)

9. Gaar, K. A., Jr., A. E. Taylor, L. J. Owens, and A. C. Guyton. 1967. Pulmonary capillary pressure and filtration coefficient in the isolated perfused lung. Am. J. Physiol. 213 : 910-914.

10. Gornall, A. G., C. J. Bardawill, and M. M. David. 1949. Determination of serum proteins by means of the Biuret reaction. J. Biol. Chem. 177: 751-766.

11. Goresky, C. A., R. F. P. Cronin, and B. E. Wangel. 1969. Indicator dilution measurements of extravascular water in lungs. J. Clin. Invest. 48: 487-501.

12. Chinard, F. P., T. Enns, and M. F. Nolan. 1962. Pulmonary extravascular water volumes from transit time and slope data. J. Appl. Physiol. 17: 179-183.

13. Storey, W., F., and N. C. Staub. 1962. Ventilation of terminal air units. J. Appl. Physiol. 17: 391-397.

14. Crosby, W., J. I. Mann, and F. W. Furth. 1954. Standardizing a method for clinical hemoglobinometry. U. S. Armed Forces Med. J. 5: 693-703.

15. Pearce, M. L., J. Yamashita, and J. Beazell. 1965. Measurement of pulmonary edema. Circulation Res. 16: $482-488$.
16. Snedecor, G., and W. Cochran. 1967. Statistical Methods. Iowa State University Press, Ames, Iowa. 6th Edition.

17. Allen, L. 1967. Lymphatics and lymphoid tissues. Annu. Rev. Physiol. 29 : 197-224.

18. Garlick, D. G., and E. M. Renkin. 1970. Transport of large molecules from plasma to interstitial fluid and lymph in dogs. Am. J. Physiol. 219: 1595-1605.

19. Boyd, R. D. H., J. R. Hill, P. W. Humphreys, I. C. S. Normand, E. O. R. Reynolds, and L. B. Strang. 1969. Permeability of lung capillaries to macromolecules in foetal and newborn lambs and sheep. J. Physiol. (Lond.). 201 : 567-588.

20. Drinker, C. K. 1942. Lane medical lectures: the lymphatic system, its part in regulating composition and volume of tissue fluid. Med. Sci. 4: 137-235.

21. Mayerson, H., R. Patterson, A. McKee, S. LeBrie, and P. Mayerson. 1962. Permeability of lymphatic vessels. Am. J. Physiol. 203 : 98-106.

22. Shirley, H. M., Jr., C. G. Wolfram, K. Wasserman, and H. S. Mayerson. 1957. Capillary permeability to macromolecules: stretched pore phenomenon. Am. J. Physiol. 190 : 189-197.

23. Pietra, G. G., J. P. Szidon, M. M. Leventhal, and A. P. Fishman. 1969. Hemoglobin as a tracer in hemodynamic pulmonary edema. Science (Wash. D. C.). 166: 1643-1646.

24. Arturson, G., T. Groth, and G. Grotte. 1972. The functional ultrastructure of the blood-lymph barrier. Computer analysis of data from dog heart-lymph experiments using theoretical models. Acta Physiol. Scand. Suppl. 374: 1-30.

25. Blake, L. H., and N. C. Staub. 1972. Modeling of steady state pulmonary transvascular fluid and protein exchange in unanesthetized sheep. Physiologist. 15: 88. (Abstr.)

26. Cottrell, T. S., R. Levine, R. M. Senior, J. Wiener, D. Spiro, and A. P. Fishman. 1967. Electron microscopic alterations at the alveolar level in pulmonary edema. Circ. Res. 21 : 783-797.

27. Cunningham, A., and J. Hurley. 1972. Alpha-naphthyl thiourea-induced pulmonary oedema in the rat: a topographical and electron-microscope study. J. Pathol. 106: 25-35.

28. Hovig, T., A. Nicolaysen, and G. Nicolaysen. 1971. Ultrastructural studies of the alveolar-capillary barrier in isolated plasma-perfused rabbit lungs. Effects of EDTA and of increased capillary pressure. Acta Physiol. Scand. 82 : 417-432.

29. Hyde, D. M. 1973. A freeze-fracture study of ozoneinduced morphological change in primate lung. 31st Annual Proceedings of the Electron Microscopy Society of America. C. Arceneaux, editor. Louisiana State University Press, Baton Rouge, La.

30. Staub, N. 1970. The pathophysiology of pulmonary edema. Hum. Pathol. 1 : 419-432.

31. Guyton, A. C., and A. W. Lindsey. 1959. Effect of elevated left atrial pressure and decreased plasma protein concentration on the development of pulmonary edema. Circ. Res. 7 : 649-657.

32. Riordan, I. F., and G. Walters. 1968. Pulmonary edema in bacterial shock. Lancet. $1: 719-721$.

33. Chien, S., D. G. Sinclair, R. J. Dellenback, C. Chang, B. Peric, S. Usami, and M. I. Gregersen. 1964. Effect of endotoxin on capillary permeability to macromolecules. Am. J. Physiol. 207: 518-522. 
34. Snell, J. D., Jr., and L. H. Ramsey. 1969. Pulmonary edema as a result of endotoxemia. Am. J. Physiol. 217: 170-175.

35. Reeves, J. T., F. S. Daoud, and M. Estridge. 1972. Pulmonary hypertension caused by minute amounts of endotoxin in calves. J. Appl. Physiol. 33: 739-743.

36. Petersdorf, R., and J. Shulman. 1964. The role of tolerance in the action of bacterial endotoxins. Bacterial Endotoxins Proc. Symp. 1 : 482-499.

37. Pietra, G. G., J. P. Szidon, M. M. Leventhal, and A. P. Fishman. 1971. Histamine and interstitial pulmonary edema in the dog. Circ. Res. 29: 323-337.

38. Majno, G., V. Gilmore, and M. Leventhal. 1967. On the mechanism of vascular leakage caused by histaminetype mediators. A microscopic study in vivo. Circ. Res. 21 : 833-847.
39. Bourne, H. R. 1972. Leukocyte cyclic AMP : pharmacological regulation and possible physiological implication. In Prostaglandins in Cellular Biology, P. Ramwell and B. Phariss, editors. Plenum Press, New York. 111135.

40. Kedem, O., and A. Katchalsky. 1958. Thermodynamic analysis of the permeability of biological membranes to non-electrolytes. Biochim. Biophys. Acta. 27: 229-246.

41. West, J. B., C. T. Dollery, and A. Naimark. 1964. Distribution of blood flow in isolated lung: relation to vascular and alveolar pressures. J. Appl. Physiol. 19: 713-724.

42. Pandeli, A., W. A. Neely, and J. D. Hardy. 1968. Interstitial fluid pressure changes in endotoxin shock. Surgery (St. Louis). 63: 938-941. 